Correspondence

Malabi M. Venkatesan

malabi.venkatesan@na.amedd. army.mil

Received 1 November 2005

Revised 30 November 2005 Accepted 7 December 2005

\section{Subtractive hybridization and optical mapping of the enterotoxigenic Escherichia coli H10407 chromosome: isolation of unique sequences and demonstration of significant similarity to the chromosome of $E$. coli $\mathrm{K}-12$}

\author{
Qing Chen, ${ }^{1}$ Stephen J. Savarino ${ }^{2}$ and Malabi M. Venkatesan ${ }^{1}$
}

Department of Enteric Infections, Division of Communicable Diseases and Immunology, Walter Reed Army Institute of Research ${ }^{1}$ and Enteric Diseases Department, Naval Medical Research Center $^{2}$, Silver Spring, MD, USA

\begin{abstract}
Enterotoxigenic Escherichia coli (ETEC) is a primary cause of diarrhoea in infants in developing countries and in travellers to endemic regions. While several virulence genes have been identified on ETEC plasmids, little is known about the ETEC chromosome, although it is expected to share significant homology in backbone sequences with $E$. coli K-12. In the absence of genomic sequence information, the subtractive hybridization method and the more recently described optical mapping technique were carried out to determine the degree of genomic variation between virulent ETEC strain H10407 and the non-pathogenic E. coli K-12 strain MG1655. In one round of PCRbased suppression subtractive hybridization, 153 fragments representing sequences unique to strain $\mathrm{H} 10407$ were identified. BLAST searches indicated that few unique sequences showed homology to known pathogenicity island genes identified in related E. coli pathogens. A total of 65 fragments contained sequences that were either linked to hypothetical proteins or showed no homology to any known sequence in the database. The remaining sequences were either phage or prophage related or displayed homology to classifiable genes that function in various aspects of bacterial metabolism. The 153 unique sequences showed variable distribution across different ETEC strains including ETEC strain B7A, which is attenuated in virulence and lacked several H10407-specific sequences. Restriction-enzyme-based optical maps of strain $\mathrm{H} 10407$ were compared to in silico restriction maps of strain MG1655 and related E. coli pathogens. The $5 \cdot 1 \mathrm{Mb}$ ETEC chromosome was $\sim 500 \mathrm{~kb}$ greater in length than the chromosome of $E$. coli $\mathrm{K}-12$, collinear with it and indicated several discrete regions where insertions and/or deletions had occurred relative to the chromosome of strain MG1655. No major inversions, transpositions or gross rearrangements were observed on the ETEC chromosome. Based on comparisons with known genomic sequences and related optical-map-based restriction site similarity, the sequence of the $\mathrm{H} 10407$ chromosome is expected to demonstrate $\sim 96 \%$ identity with that of E. coli $\mathrm{K}-12$.
\end{abstract}

Abbreviations: $\mathrm{CF}$, colonization factor; CFA, colonization factor antigen; EHEC, enterohaemorrhagic Escherichia coli; ETEC, enterotoxigenic E. coli; LEE, locus of enterocyte effacement; LT, heat-labile enterotoxin; PAl, pathogenicity island; PCF, putative colonization factor; $\mathrm{SSH}$, suppression subtraction hybridization; ST, heat-stable enterotoxin; UPEC, uropathogenic E. coli.

The GenBank/EMBL/DDBJ accession numbers for the 153 sequences unique to the $\mathrm{H} 10407$ chromosome reported in this paper are listed in Table 2. The GenBank/EMBL/DDBJ accession number for strain $\mathrm{H} 10407$ eaeH gene is DQ109813.

A fuller version of Table 2 is available as supplementary data with the online version of this paper.

\section{INTRODUCTION}

Enterotoxigenic Escherichia coli (ETEC) causes watery diarrhoea in humans and animals and is responsible for 400000 to 800000 deaths per year (Gilligan, 1999). Approximately 280 million episodes occur annually among children under age 5 years in developing countries (Wenneras \& Erling, 2004). ETEC is also the leading cause of diarrhoea among travellers from industrialized countries (Arduino \& DuPont, 1993; Cartwright, 1993; Wolf et al., 1993).

ETEC infection is acquired by consumption of contaminated food or water. The bacteria attach to and colonize the small intestine using a heterogeneous group of surface 
colonization factor antigens (CFAs) (Knutton et al., 1987). CFAs and putative colonization factors (PCFs), jointly referred to as colonization factors ( $\mathrm{CFs}$ ), mediate the attachment of bacteria to the intestinal mucosa, whereas heat-labile (LT) and heat-stable (ST) enterotoxins induce diarrhoea (Levine et al., 1983). There are different serotypes of ETEC strains producing a variety of CFs (Wolf, 1997). ETEC strain H10407 (O78:H11:CFA/I: $\left.\mathrm{LT}^{+}: \mathrm{STIb}^{+}\right)$, a clinical isolate from a patient in Bangladesh (Evans \& Evans, 1973), is a prototypic virulent strain, which has been tested in oral challenge studies and shown to cause diarrhoea in humans (Tacket et al., 1988)). Like most ETEC, strain H10407 carries plasmids and these encode most of the virulence determinants described so far such as CFs, LT and ST (Evans et al., 1975; Smith et al., 1979; Yamamoto \& Yokota, 1983). The complete annotated sequence of the ETEC plasmids is not yet available; it will undoubtedly reveal additional genes with functions associated with the determination of virulence. There is some evidence to suggest that the antibacterial immunity induced by ETEC is to a large extent CF-specific (Freedman et al., 1998).

Despite the clinical importance of ETEC, little is known about the ETEC chromosome. Among the few virulenceassociated loci that have been identified are tia and tib, two separate loci that mediate adhesion and invasion of strain H10407 to cultured epithelial cells, and the gsp operon, which encodes a type II secretion pathway for regulating the secretion of LT (Elsinghorst \& Kopecko, 1992; Elsinghorst \& Weitz, 1994; Lindenthal \& Elsinghorst, 1999; Tauschek et al., 2002). The tia locus is not universally distributed, being present in about $40 \%$ of ETEC strains (Fleckenstein et al., 1996). The tib locus encodes a glycoprotein TibA, which has been implicated in bacterial autoaggregation and biofilm formation (Sherlock et al., 2005). DNA microarray-based genomic hybridization has been used to demonstrate the extent of E. coli K-12 genes that are missing in strain $\mathrm{H} 10407$ (Fukiya et al., 2004). The loss of K-12 genes may be related to adaptive genomic changes that facilitate acquisition of the virulent phenotype (Dobrindt et al., 2003; Fukiya et al., 2004). Since the completion of the chromosomal sequencing of the laboratory E. coli K-12 strain MG1655 (Blattner et al., 1997), several pathogenic E. coli genomes have been sequenced. These include genomes of enterohaemorrhagic E. coli (EHEC), Shigella and uropathogenic E. coli (UPEC) strains (Hayashi et al., 2001; Jin et al., 2002; Perna et al., 2001; Wei et al., 2003; Welch et al., 2002). Comparison of these genomes with the MG1655 sequence has demonstrated that while these genomes share a common E. coli K-12 backbone sequence, there is a surprising level of diversity. The differences in overall gene content are attributable to horizontal gene transfer events which occur by the acquisition of various virulence-associated plasmids, bacteriophages and pathogenicity islands (PAIs) (Dobrindt \& Reidl, 2000).

The complete annotated genome sequence of a virulent ETEC strain is not yet available. However, several techniques, which are sequence-based, can be used to isolate pathogen-specific DNA sequences and also to obtain a broad view of the genome structure as it relates to strain MG1655. Suppression subtractive hybridization (SSH) has been successfully used to isolate DNA fragments that are present in one set of DNA sequences (tester DNA, in this case the ETEC chromosomal DNA) but not in another (driver DNA, in this case strain MG1655). The unique ETEC-specific chromosomal sequences can be compared with and annotated in relation to the sequenced enteropathogenic E. coli (EPEC), EHEC, UPEC and Shigella strains (Diatchenko et al., 1996; Winstanley, 2002). Another novel technique to compare two related genomes is optical mapping, which generates high-resolution ordered restriction maps from single DNA molecules including whole bacterial chromosomes (Cai et al., 1998; Lin et al., 1999), and provides a powerful approach to comparative genomic analysis. Comparison of an optical map of a strain with in silico restriction maps of closely related sequenced strains reveals major genomic structural variations such as deletions, inversions, translocations, duplications and gross rearrangements (Zhou et al., 2004a). When these two techniques were applied to the ETEC chromosome, the results demonstrated that the H10407 chromosome is highly homologous to that of strain MG1655, more so than any of the other pathogenic E. coli strains. It is hoped that these studies will complement the genome sequencing data of strain $\mathrm{H} 10407$ when it is completed.

\section{METHODS}

Bacterial strains, plasmids, culture conditions. Bacterial strains used in this study are listed in Table 1. E. coli strains were grown at $37^{\circ} \mathrm{C}$ in Luria-Bertani (LB) broth, or on LB agar supplemented with appropriate antibiotics or substrates for screening at the following final concentrations: ampicillin, $100 \mu \mathrm{g} \mathrm{ml}^{-1}$; IPTG, $0 \cdot 2 \mathrm{mM}$; $\mathrm{X}-\mathrm{Gal}, 80 \mu \mathrm{g} \mathrm{ml}^{-1}$. Plasmids pHC79 and pCRII-TOPO (Invitrogen) were used to construct the cosmid library and the subtractive library, respectively.

Recombinant DNA techniques. Recombinant DNA methods including restriction-enzyme digestion, ligation reactions, agarose gel electrophoresis and plasmid analysis were performed following standard protocols (Sambrook \& Russell, 2001) or the manufacturer's instructions. Plasmid and cosmid purification were performed with QIAprep Miniprep kit (Qiagen) and Qiagen Plasmid Midi kit, respectively. Elution of DNA fragments from agarose gels were performed with the QIAquick gel extraction kit (Qiagen).

Genomic DNA preparation and chromosomal DNA purification. Genomic DNA from strains H10407 and MG1655 was isolated by using the Genomic-Tip 100/G kit (Qiagen), according to the manufacturer's protocol. To separate H10407 chromosomal DNA from plasmids, the total genomic DNA was fractionated on $0.5 \%$ (w/v) agarose gel and the DNA eluted with the QIAquick gel extraction kit. To reduce the size, the chromosomal DNA was sheared by repeated passage through a 21-gauge needle 8-10 times.

Subtractive hybridization and screening. SSH was carried out using the PCR-Select Bacterial Genomic Subtraction Kit (Clontech) and essentially following the manufacturer's instructions. H10407 chromosomal DNA was used as the tester and MG1655 DNA was used as the driver DNA. During SSH, a high annealing temperature 
Table 1. Bacterial strains used in this study

\begin{tabular}{|c|c|c|}
\hline Strains & Genotype, serotype or phenotype & Source or ref. \\
\hline HB101 & $\begin{array}{l}\mathrm{F}^{-} \Delta(\text { gpt-proA }) 62 \text { leuB6 glnV44 ara-14 galK2 lacY1 } \\
\Delta(\text { mcrC-mrr }) \text { rpsL20 }\left(\text { Str }^{\mathrm{R}}\right) x y l-5 \text { mtl-1 recA13 }\end{array}$ & WRAIR $^{*}$ \\
\hline \multicolumn{3}{|l|}{ ETEC strains } \\
\hline H10407 & O78: K80:H11, LT, ST, CFA/I & WRAIR (Evans \& Evans, 1973) \\
\hline E20738A & O114:H21, LT, CS17 & WRAIR (McConnell et al., 1990) \\
\hline B7A & O148:H28, LT, ST, CS6, PCFO148 & $\begin{array}{l}\text { WRAIR (Knutton et al., 1987; } \\
\text { Levine et al., 1979) }\end{array}$ \\
\hline E23477A & O139:H28, LT, ST, CS1, CS3 & WRAIR (Levine et al., 1984) \\
\hline WS2010A & $\mathrm{O} 8: \mathrm{H} 9, \mathrm{ST}, \mathrm{CS} 3$ & WRAIR \\
\hline C91f & O6:H16, LT, ST, CS2 & WRAIR (Smyth, 1982) \\
\hline WS1833C & O8:H9, LT, ST, CS3 & WRAIR \\
\hline $1392 / 75-2 \mathrm{~A}$ & O6:H16, CS1, CS3 & WRAIR \\
\hline
\end{tabular}

${ }^{\star}$ WRAIR, Walter Reed Army Institute of Research, Silver Spring, MD, USA.

of $63{ }^{\circ} \mathrm{C}$ was used to enrich for the recovery of H10407-specific unique sequences. The PCR products obtained from SSH, representing tester-specific sequences, were cloned into pCRII-TOPO (Invitrogen), transformed into E. coli strain TOP10F' and the transformation mixture plated on LB agar plates containing $0.2 \mathrm{mM}$

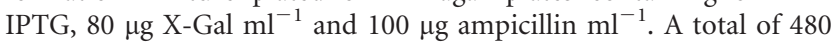
white colonies were randomly selected for plasmid preparation and sequencing using vector-based primers flanking the cloning site on the vector.

Construction and screening of cosmid library. A partial Sau3AI digest of the H10407 genomic DNA was cloned into the cosmid vector pHC79. In vitro packaging was performed with Gigapack III Plus (Stratagene), according to the manufacturer's protocol. To screen the cosmid library for H10407-specific unique sequences, $1 \times 10^{3}$ colonies were replicated onto a $0 \cdot 2 \mu \mathrm{m}$ nitrocellulose filter (Bio-Rad). Immobilized colonies were lysed by floating the filter on $10 \%(\mathrm{w} / \mathrm{v})$ SDS for $5 \mathrm{~min}$, dried and hybridized to labelled probes.

RNA preparation and cDNA synthesis. Total RNA from strain H10407 was prepared from exponential-phase cultures grown in LB medium at $37^{\circ} \mathrm{C}$ using the Qiagen Midi Kit according to the manufacturer's instructions. To synthesize the first strand of cDNA, $20 \mu \mathrm{g}$ RNA was annealed with random hexamers at $37^{\circ} \mathrm{C}$ for $10 \mathrm{~min}$, followed by incubation at $70^{\circ} \mathrm{C}$ for $10 \mathrm{~min}$ and chilling on ice for $5 \mathrm{~min}$. After the initial annealing step, cDNA synthesis was carried out using a kit containing Cyscript reverse transcriptase (Amersham). Second-strand cDNA synthesis was carried out with Klenow enzyme (Roche) at $37^{\circ} \mathrm{C}$ for $1 \mathrm{~h}$. The resulting doublestranded cDNA was purified using the QIAquick PCR Purification Kit (Qiagen) and eluted into $50 \mu \mathrm{H}_{2} \mathrm{O}$.

Preparation of DNA from different ETEC strains. Approximately $6 \mathrm{mg}$ genomic DNA from 11 different ETEC strains was partially digested with 80 units EcoRI at $37^{\circ} \mathrm{C}$ overnight. The digested DNAs were labelled and used as probes against the H10407-specific sequences on a DNA dot blot.

Labelling of probes. Probes were labelled with biotin-14-dCTP using the BioPrime DNA Labelling System (Invitrogen). cDNA derived from $20 \mu \mathrm{g}$ RNA, $250 \mathrm{ng}$ digested genomic DNA or PCR-amplified H10407-specific sequences were used as probes. Unincorporated dNTPs and fragments $<30 \mathrm{bp}$ were removed using Spin-50 column (Biomax).

PCR amplification, dot blot hybridization and image analysis. The 504 bp eae gene fragment was amplified by PCR using primers eae-F ( $5^{\prime}$-GATATTAATTTATCGACGATTTGGTC-3') and eae-R (5'-GCGCTCCGACCTGACCAAATGCCAG-3') and genomic DNA of E. coli O157:H7 EDL933 as template. The PCR-amplified eae DNA was used as a negative control for the dot blot hybridizations since the eae gene is absent in the H10407 chromosome. Nested primers 1 and 2 provided in the CLONTECH PCR-Select Bacterial Genomic Subtraction Kit were used to PCR amplify the individual unique sequences in the H10407 subtractive library. The PCR products were used to prepare DNA dot blots and, in some cases, labelled and used as probes.

To prepare the DNA dot blot, PCR products were heated at $98^{\circ} \mathrm{C}$ for 5 min and chilled on ice. Then $1 \mu \mathrm{l}$ denatured PCR product was transferred to a $0 \cdot 2 \mu \mathrm{m}$ nitrocellulose filter (Bio-Rad). The DNA on the filter was denatured and neutralized using routine methods and crosslinked to the membrane using a Gene Linker UV Chamber (Bio-Rad). Prehybridization was carried out in $6 \times$ SSC, $5 \times$ Denhardt's reagent, $50 \%(\mathrm{v} / \mathrm{v})$ formamide, $100 \mu \mathrm{g}$ denatured salmon sperm DNA ml ${ }^{-1}$, at room temperature for $1 \mathrm{~h}$. Biotin-labelled probe $\left(50 \mathrm{ng} \mathrm{ml}^{-1}\right)$ was added, and hybridization was carried out at room temperature overnight. The filter was washed under stringent conditions $[2 \times$ SSC, $1 \%(\mathrm{w} / \mathrm{v}) \operatorname{SDS}$ at $65^{\circ} \mathrm{C}$ for $20 \mathrm{~min}$, followed by $0 \cdot 2 \times \mathrm{SSC}, 0 \cdot 1 \%(\mathrm{w} / \mathrm{v})$ 
SDS at $65^{\circ} \mathrm{C}$ for $20 \mathrm{~min}$. The signal was developed by treatment with streptavidin-alkaline phosphatase (Perkin Elmer Life Science) and Lumi-Phos WB chemiluminescent substrate (Pierce), followed by maximal exposure to CL-X-Posure Film (Pierce) overnight. The X-ray image was scanned (ScanMaker 5700, Microtec), and the intensity of each dot was measured on a Macintosh computer using the NIH Image program (developed at the U S National Institutes of Health and available on the Internet at http://rsb.info.nih.gov/nih-image/).

DNA sequencing, primer walking and data analysis. DNA sequences were determined by the dideoxy-chain-termination method using the Big Dye Terminator v3.1 DNA sequencing kit (Applied Biosystems) on an automated sequencer, ABI Prism 3100 (Applied Biosystems). The sequence of the eaeH gene was completed by primer-walking on selected cosmids. DNA sequence data were analysed with the Sequencher program (version 4.2 for Macintosh, Gene Codes Corp.) to remove the vector sequence and the redundant sequences. The H10407-specific sequences were those determined to show no significant alignment to the E. coli K-12 strain MG1655 (NC_000913). Database searches for homologous genes and proteins were performed by using the National Center for Biotechnology Information (NCBI) BLAST server.

Optical mapping of the H10407 chromosome. The optical maps of strain $\mathrm{H} 10407$ with BamHI, BsiWI and EagI restriction enzymes were constructed commercially by OpGen. In this method, purified chromosomal DNA is deposited onto an optical mapping surface such as a derivatized glass coverslip, using a microfluidic device. The DNA is encased in a thin layer of acrylamide and incubated with restriction enzymes in a humidified chamber at $37^{\circ} \mathrm{C}$ for 60-120 min. The digested DNA is labelled with fluorescent YOYO-1 and the individual molecules imaged with fluorescence microscopy. Digital images are collected by a fully automated image-acquisition system and image files are processed to create single-molecule optical maps using OpGen's software programs. Individual molecule restriction maps were overlapped by optical map assembler software. Briefly, this assembler works by comparing single-molecule restriction maps and estimating the probability that these two molecules arose from overlapping genomic locations given a description of the likelihood of possible errors resulting from incomplete digestion of the molecule, spurious cuts of the molecule, and errors in the sizing estimates of the resulting fragments. Through repeated overlapping of molecules, the assembler reconstructs the ordered restriction map of the genome. This technique has been previously applied to map other bacterial genomes (Lai et al., 1999; Lim et al., 2001; Lin et al., 1999). The map alignments between two different strains were generated with a dynamic programming algorithm based upon previous methods (Myers \& Huang, 1992; Tang \& Waterman, 2001; Waterman et al., 1984). This method finds the optimal alignment of two restriction maps according to a scoring model that incorporates fragment sizing errors, false and missing cuts, and missing small fragments. For a given alignment, the score is proportional to the log of the length of the alignment, penalized by the differences between the two maps, such that longer, better-matching alignments will have higher scores. The regions of gaps, insertions and deletions were obtained by comparing the ETEC strain H10407 map to the in silico restriction map of E. coli K-12 strain MG1655 using OpGen's MapViewer software, similar to previously reported work (Reslewic et al., 2005).

\section{RESULTS}

\section{Subtractive hybridization of strain $\mathrm{H} 10407$ chromosomal DNA with strain MG1655}

SSH was carried out between the gel-purified H10407 chromosomal DNA, referred to as the tester DNA, and chromosomal DNA from strain MG1655, referred to as the driver or reference DNA. The tester-specific H10407 subtracted DNA fraction was obtained after two rounds of sequential hybridizations with driver DNA in excess. PCR amplification using 23S RNA-specific sequence primers demonstrated that the abundance of conserved sequences in the H10407 subtracted DNA fraction was reduced dramatically (data not shown). The H10407-specific sequences were cloned and plasmid digests of 364 of 480 randomly selected recombinant clones contained insertions of different sizes. DNA sequencing indicated that 194 clones were distinct and 153 of the 194 distinct clones (79\%) were unique to strain H10407 as determined by lack of significant homology (expected value $>1 \mathrm{e}-40$ ) to strain MG1655. The sizes of the 153 fragments ranged from $78 \mathrm{bp}$ to $1070 \mathrm{bp}$ (mean $391 \mathrm{bp}$ ). The combined size of the sequenced fragments that were contained in the 153 clones was $\sim 60 \mathrm{~kb}$ and these sequences demonstrated a mean $\mathrm{G}+\mathrm{C}$ content of $51 \mathrm{~mol} \%$, although individual sequences varied in $\mathrm{G}+\mathrm{C}$ content (see the supplementary table available with the online version of the paper). Note that the sequences in the unique clones represented only portions of individual genes or genetic elements and were by no means complete gene sequences.

\section{The H10407 chromosome lacks genes observed in known PAls}

Based on BLASTN search, the 153 H10407-specific DNA sequences were grouped into different categories as shown in Table 2. Although several hypothetical and unknown sequences were identified, most known virulence-associated genes on PAIs, previously identified in E. coli pathogens such as ETEC, EPEC, Shigella and UPEC strains, do not appear to have been recovered in the H10407 subtractive library (Schmidt \& Hensel, 2004).

Group I: sequences that are part of genes previously described in H10407. Previously described chromosomal sequences corresponding to the gsp operon and the tia and tib loci were recovered in the H10407-specific SSH library, validating the use of the SSH technique. The gsp operon encodes a type II secretion system for LT secretion (Tauschek et al., 2002). The combined sizes of the genes to which some homology was seen with the unique sequences comprised two-thirds of the $8.5 \mathrm{~kb}$ gsp operon. This particular operon is lacking in E. coli $\mathrm{K}-12$. In addition, fragments with sequences homologous to the eat $A$ gene, encoded on the $92 \mathrm{~kb}$ plasmid (Patel et al., 2004), were also recovered in the H10407 SSH library. The recovery of these fragments indicates a low level of plasmid contamination in the chromosomal DNA preparations, which probably occurred during extraction of the chromosomal DNA from agarose gels. However, other known plasmid genes such as the CFA/I operon, ST and LT were not recovered in the subtractive library. Seven of nine ETEC fragment sequences that fall into the group I category are of chromosomal origin. Thus, as expected, 
Table 2. Analysis of ETEC H10407-specific DNA fragments obtained from the subtractive library

A fuller version of this table is available as supplementary data with the online version of the paper.

\begin{tabular}{|c|c|c|c|c|c|c|}
\hline Frag. no. & Size (bp) & $\mathrm{E}^{*}$ & $\mathrm{~B} 7 \mathrm{~A} \dagger$ & Genes/proteins of best BLAST hit $\ddagger$ & $E$-value $\S$ & Accession no. \\
\hline \multicolumn{7}{|c|}{ I. Genes described in ETEC H10407 (9) } \\
\hline 284 & 627 & $\mathrm{E}$ & $\mathrm{P}$ & $\begin{array}{l}\text { (RIl:1-296) gspD, hypothetical type II } \\
\text { secretion protein, ETEC H10407 }\end{array}$ & $\mathrm{e}-162$ & CZ548273 \\
\hline 213 & 294 & $\mathrm{E}$ & $\mathrm{P}$ & $\begin{array}{l}g s p D \text {, hypothetical type II secretion } \\
\text { protein, ETEC H10407 }\end{array}$ & $\mathrm{e}-164$ & CZ548270 \\
\hline 278 & 337 & $\mathrm{E}$ & $\mathrm{P}$ & $\begin{array}{l}\text { (R:1-249) gspG, hypothetical type II } \\
\text { secretion protein, ETEC H10407 }\end{array}$ & $\mathrm{e}-125$ & CZ548272 \\
\hline 633 & 211 & $\mathrm{E}$ & & tia, ETEC H10407 & e-107 & CZ548280 \\
\hline 511 & 648 & $\mathrm{E}$ & & (R:9-257) tibA, ETEC H10407 & $\mathrm{e}-145$ & CZ548279 \\
\hline 301 & 483 & $\mathrm{E}$ & & tibA, ETEC H10407 & 0 & CZ548274 \\
\hline \multicolumn{7}{|c|}{ II. Genes with known functions (34) } \\
\hline 609 & 173 & $\mathrm{E}$ & $\mathrm{P}$ & $\begin{array}{l}\text { agaA, } N \text {-acetylgalactosamine-6-phosphate } \\
\text { deacetylase, E. coli C }\end{array}$ & $2 \mathrm{e}-89$ & CZ305760 \\
\hline 222 & 273 & & $\mathrm{P}$ & agaE, E. coli $\mathrm{C}$ & $\mathrm{e}-143$ & CZ305641 \\
\hline 293 & 213 & $\mathrm{E}$ & & altD, D-arabitol dehydrogenase, E. coli C & $\mathrm{e}-115$ & CZ305666 \\
\hline 259 & 318 & $\mathrm{E}$ & $\mathrm{P}$ & atlK, xylulose kinase, E. coli $\mathrm{C}$ & $\mathrm{e}-171$ & CZ305658 \\
\hline 660 & 531 & & & $\begin{array}{l}r t l D \text {, ribitol dehydrogenase; } r t l K \text {, ribitol } \\
\text { kinase, } E \text {. coli C }\end{array}$ & 0 & CZ305775 \\
\hline 672 & 288 & $\mathrm{E}$ & $\mathrm{P}$ & $\begin{array}{l}\text { deoQ, putative transcriptional regulator, } \\
\text { E. coli strain AL862 }\end{array}$ & $\mathrm{e}-140$ & CZ305780 \\
\hline 584 & 203 & & & $\begin{array}{l}\text { Putative beta-ketoacyl-ACP synthase, } \\
\text { E. coli O157: H7 EDL933 }\end{array}$ & $\mathrm{e}-102$ & CZ305750 \\
\hline 447 & 347 & $\mathrm{E}$ & $\mathrm{P}$ & $\begin{array}{l}\text { traD, bacterial conjugation membrane } \\
\text { protein, plasmid R100 }\end{array}$ & $\mathrm{e}-155$ & CZ305714 \\
\hline 239 & 421 & $\mathrm{E}$ & $\mathrm{P}$ & traI, E. coli plasmid pC15-1 & 0 & CZ305649 \\
\hline 452 & 444 & $\mathrm{E}$ & $\mathrm{P}$ & traK for pilus biogenesis, plasmid R100 & 0 & CZ305715 \\
\hline 459 & 464 & $\mathrm{E}$ & $\mathrm{P}$ & traL, E. coli plasmid p1658/9 & $\mathrm{e}-146$ & CZ305717 \\
\hline 483 & 853 & $\mathrm{E}$ & $\mathrm{P}$ & $\begin{array}{l}\text { (R:1-369) silA, putative inner-membrane } \\
\text { proton/cation antiporter, Salmonella } \\
\text { typhimurium plasmid pMG101 }\end{array}$ & 0 & CZ305728 \\
\hline 667 & 961 & $\mathrm{E}$ & $\mathrm{P}$ & $\begin{array}{l}\text { (R:1-570) silC, putative outer-membrane } \\
\text { protein, Klebsiella pneumoniae plasmid } \\
\text { pLVPK }\end{array}$ & 0 & CZ305778 \\
\hline 360 & 342 & & & $\begin{array}{l}\text { silC, putative outer-membrane protein, } \\
\text { Sal. typhimurium plasmid pMG101 }\end{array}$ & 0 & CZ305687 \\
\hline 411 & 129 & $\mathrm{E}$ & & $\begin{array}{l}\text { silC, putative outer-membrane protein, } \\
\text { Sal. typhimurium plasmid pMG101 }\end{array}$ & $5 e-46$ & CZ305700 \\
\hline 398 & 144 & $\mathrm{E}$ & & fliC, flagellin, E. coli strain F199 & $1 \mathrm{e}-47$ & CZ305697 \\
\hline
\end{tabular}


Table 2. cont.

\begin{tabular}{|c|c|c|c|c|c|c|}
\hline Frag. no. & Size (bp) & $\mathbf{E}^{\star}$ & $\mathrm{B} 7 \mathrm{~A} \dagger$ & Genes/proteins of best BLAST hit $\neq$ & $E$-value $\$$ & Accession no. \\
\hline 629 & 153 & $\mathrm{E}$ & $\mathrm{P}$ & fliC, flagellin, E. coli strain F199 & $2 e-67$ & CZ305766 \\
\hline 345 & 246 & $\mathrm{E}$ & & $\begin{array}{l}\text { fliD, filament capping protein, Sal. } \\
\text { typhimurium LT2 }\end{array}$ & $3 e-33$ & CZ305682 \\
\hline 309 & 503 & $\mathrm{E}$ & & $\begin{array}{l}\text { (R:2-229) SapA-like putative structure } \\
\text { protein, E. coli CFT073 }\end{array}$ & $9 e-29$ & CZ305670 \\
\hline 361 & 442 & & & $\begin{array}{l}\text { (R:229-444) putative membrane protein, } \\
\text { enterobacteria phage epsilon } 15\end{array}$ & $1 e-83$ & CZ305688 \\
\hline 551 & 665 & $\mathrm{E}$ & & $\begin{array}{l}\text { (R:325-655) putative autotransporter, } \\
\text { S. flexneri 2a SRL PAI }\end{array}$ & $\mathrm{e}-177$ & CZ305744 \\
\hline 238 & 418 & $\mathrm{E}$ & $\mathrm{P}$ & $\begin{array}{l}\text { Putative autotransporter, S. flexneri 2a } \\
\text { SRL PAI }\end{array}$ & 0 & CZ305648 \\
\hline 219 & 636 & $\mathrm{E}$ & $\mathrm{P}$ & $\begin{array}{l}\text { (R:390-636) adhesin AIDA-I precursor, } \\
\text { E. coli O157:H7 }\end{array}$ & $\mathrm{e}-126$ & CZ305638 \\
\hline 363 & 636 & $\mathrm{E}$ & $\mathrm{P}$ & $\begin{array}{l}\text { eaeH, putative adhesin, E. coli } \mathrm{O} 157: \mathrm{H} 7 \\
\text { EDL933 }\end{array}$ & 0 & CZ305689 \\
\hline 673 & 493 & $\mathrm{E}$ & $\mathrm{P}$ & $\begin{array}{l}\text { Putative derepression protein, E. coli } \\
\text { O157: H7 }\end{array}$ & 0 & CZ305781 \\
\hline 671 & 148 & & $\mathrm{P}$ & $\begin{array}{l}\text { Putative outer-membrane usher protein, } \\
\text { E. coli O157:H7 }\end{array}$ & $9 e-51$ & CZ305779 \\
\hline 312 & 276 & $\mathrm{E}$ & $\mathrm{P}$ & $\begin{array}{l}\text { Putative peptidase, Serratia marcescens } \\
\text { plasmid R478 }\end{array}$ & $\mathrm{e}-148$ & CZ305671 \\
\hline 392 & 413 & & & Putative peptide synthetase, E. coli CFT073 & $4 e-98$ & CZ305696 \\
\hline 489 & 256 & & & $\begin{array}{l}\text { (R:108-256) haemolysin expression modulating } \\
\text { protein, E. coli CFT073 }\end{array}$ & $5 e-75$ & CZ305730 \\
\hline 223 & 288 & & & $\begin{array}{l}\text { (R:189-288) haemolysin expression modulating } \\
\text { protein, E. coli CFT073 }\end{array}$ & $9 e-46$ & CZ305642 \\
\hline \multicolumn{7}{|c|}{ III. Genes related to phages/prophages (45) } \\
\hline \multicolumn{7}{|c|}{ IV. Genes related to hypothetical proteins (27) } \\
\hline \multicolumn{7}{|c|}{ V. Genes with no significant hits to GenBank (3 } \\
\hline
\end{tabular}

${ }^{*}$ In vitro expression data were obtained using a dot blot of PCR-amplified DNA fragments hybridized to biotin-labelled cDNA transcribed from strain H10407 total RNA. E designates a sequence that showed two- to sevenfold greater signal intensity of hybridization compared to a negative control on the dot blot.

$\dagger$ The ETEC strain B7A (along with 10 other strains; see supplementary data) was tested in DNA dot blot hybridization for the presence of H10407-specific DNA fragments. P designates a sequence that showed more than twofold greater signal intensity over the negative control. $\ddagger$ Genes/proteins were determined by BLAST search against GenBank with the NCBI BLASTN program.

$\$ E$-value indicates the probability of the match.

IIOnly the portions of DNA fragment that showed the best hits are listed. The segment positions are shown in parentheses.

the majority of the H10407-specific sequences obtained after SSH were derived from the chromosome.

Group II: sequences that are part of genes with previously described functions. Thirty-four H10407 unique sequences show homology to genes that encode known functions. Six of the fragments showed sequence similarity to gene sequences involved in carbohydrate metabolism (agaA, agaE, altD, atlK, rtlK and deoQ), while others had homology to gene sequences involved in fatty acid biosynthesis (Table 2). Many of the H10407-specific sequences in this category showed significant similarity to homologous sequences in UPEC strain CFT073, EHEC strain EDL933, to E. coli C and to Shigella (Table 2). The H10407 sil sequences ( illA, silC) showed homology to the $\mathrm{Ag}^{+}$resistant gene cluster (sil) on Salmonella plasmid pMG101. The sil operon encodes resistance to the highly toxic metal silver, which is often used as an antimicrobial agent (Gupta et al., 2001). Other sequences isolated in the SSH library included those with homology to the flagellin genes, suggesting that the flagella assembly sequences in strain H10407 are not identical to those in E. coli K-12 (Table 2). H10407-specific DNA segments showed sequence homology to putative virulence-associated genes encoding SapA, a putative autotransporter, adhesins such as AIDA-I precursor and $\mathrm{EaeH}$, peptidase, usher proteins and haemolysin expression modulating protein, which have been identified in other pathogenic E. coli genomes (Table 2). 
Group III: sequences with homology to phage/prophage genes. At least 45 DNA fragments had sequences that showed homology to prophage sequences of known PAIs from different pathogenic E. coli strains (Table 2). Insertion elements, integrases and transposases were the major contributing sequences to this group, suggesting the presence of H10407-specific mobile elements.

Group IV: sequences with homology to genes encoding hypothetical proteins. Twenty-seven fragments had sequences that showed homology to genes encoding conserved hypothetical proteins without a predicted function. These hypothetical proteins have been previously identified during genome sequencing of UPEC, EHEC and Shigella flexneri $2 \mathrm{a}$.

Group V: sequences that do not show homology to any database sequence. This category of 38 fragments constitutes unknown sequences that did not match any sequence described in the database.

\section{Expression profile of $\mathrm{H} 10407$ subtractive library fragments}

To determine whether the sequences contained in the SSH library represented portions of transcriptionally active genes, total RNA was extracted from exponential-phase cultures of strain $\mathrm{H} 10407$ grown at $37^{\circ} \mathrm{C}$ and hybridized to a DNA dot blot containing PCR-amplified DNA of the 153 H10407specific fragments. DNA sequences which showed two- to sevenfold greater intensity of hybridization over negative control DNA are listed in Table 2 (denoted as E). The PCR-amplified eae DNA was used as a negative control for the dot blot hybridizations since the eae gene is absent in the H10407 chromosome. As expected, all the group I sequences were expressed, in agreement with previous studies (Fleckenstein et al., 1996; Lindenthal \& Elsinghorst, 1999; Patel et al., 2004; Tauschek et al., 2002). Twenty of 27 sequences in group IV and 24 of 38 sequences belonging to group V scored positive on the RNA blots, demonstrating that the group of hypothetical and unknown sequences are part of transcriptionally active genes and should be further characterized. In general, $71 \%(109 / 153)$ of the H10407specific fragments were positive on the RNA dot blots. Furthermore, sequences that did not score positive in these blots may be transcriptionally active under other growth conditions, so that the percentage of transcribed genes in the H10407 strain SSH library may be higher.

\section{Prevalence of H10407-specific sequences among other ETEC strains}

Genomic DNA from 11 clinical isolates of ETEC was labelled with biotin and hybridized to the DNA dot blot containing the H10407-specific unique sequences. Spots whose intensities were more than twofold higher than the negative control (PCR-amplified eae gene, absent in H10407) were scored as positive (denoted as $\mathrm{P}$ in Table 2). These represent sequences that are most likely present in a particular strain.
Hybridization results revealed that the presence of these unique sequences varied, most being present in some but not all strains and indicating the diversity within ETEC. The sequence corresponding to the eaeH gene was the only one in the group II category (Table 2) that hybridized to all the ETEC strains tested, indicating that this sequence is conserved. The eaeH gene encodes an intimin-like protein whose virulence function has not been characterized. The previously described $g s p$ gene sequences were detected in all 11 ETEC strains, suggesting that this is also a conserved operon, although some portions of individual genes in the gsp operon may not be identical across all ETEC strains (Table 2). The tibA sequence was seen in 4 of 10 ETEC strains tested, confirming previous observations (Fleckenstein et al., 1996). Interestingly, the plasmid-borne eat $A$ gene that was isolated in the SSH library is present in most of the ETEC strains, but not detected in strain B7A, confirming earlier studies (Patel et al., 2004).

\section{Strain H10407 does not encode the locus of enterocyte effacement (LEE) but contains putative adhesin gene eaeH}

Since the sequence corresponding to the eaeH gene appeared to be conserved in ETEC, the H10407 eaeH gene was completely sequenced using an H10407 cosmid library that was probed with fragment no. 363 (Table 2). The full-length H10407 eaeH gene encodes 1418 amino acids. This gene has been previously described in other sequenced pathogenic $E$. colistrains (CFT073, O157: H7, O157: H EDL933). In strain MG1655, however, the eaeH gene appears as a truncated copy encoding only 293 amino acids. The LEE PAI in EPEC and EHEC strains contains the eae gene (separate and distinct from eaeH), which encodes intimin, a virulenceassociated protein shown to be critical for mediating intimate attachment to the host cell (Jerse et al., 1990; Perna et al., 1998). The LEE PAI is flanked by prophage genes and sequences homologous to these flanking prophage genes were recovered in the H10407-specific SSH library. However, none of the LEE PAI-encoded virulenceassociated genes were recovered in the H10407 subtractive library and a labelled eae gene, used as a probe, did not hybridize to strain H10407. In this respect, strain H10407 is similar to UPEC strain CFT073 (Welch et al., 2002), which also lacks the major part of LEE.

\section{Comparative optical mapping to identify the deletions, insertions and mismatched regions in the H10407 chromosome relative to E. coli K-12}

To assess the overall genome structure of strain H10407, and compare it to the MG1655 sequence and other pathogenic E. coli genomes, optical maps of strain H10407 using restriction enzymes BamHI, BsiWI, and EagI were constructed by OpGen. Based on the optical maps, the predicted size of the H10407 chromosome is $5143 \mathrm{~kb}$, which is $\sim 500 \mathrm{~kb}$ larger than the $4.6 \mathrm{Mb}$ MG1655 sequence. In size, the H10407 chromosome resembles the chromosome of EHEC and UPEC strains. 
The optical mapping system is largely automated and constructs ordered restriction maps of an entire microbial genome. When such an optical map is aligned with an in silico restriction map of a closely related sequenced genome, the comparisons between the two maps reveal inversions, insertions, deletions, duplications and translocations, while also providing orientation. The resolution of optical mapping is within $6-30 \mathrm{~kb}$, which is the mean size of a restriction fragment (Zhou et al., 2004b). When the map resolution approaches 5-7 kb, a significant proportion of restriction fragments in the map will be less than $1 \mathrm{~kb}$ and thus poorly represented in the final consensus map using the current DNA mounting procedures. Optical maps omit map information less than $500 \mathrm{bp}$ in size and show sizing errors of $\sim 2-5 \%$.

The mean restriction fragment sizes of the optical maps were $10.6 \mathrm{~kb}$ by BamHI, $9 \cdot 2 \mathrm{~kb}$ by BsiWI and $18 \mathrm{~kb}$ by EagI. The three optical maps revealed some differences in the extent and location of map homology when they were compared to the in silico maps of E. coli K-12. The BamHIand BsiWI-generated optical maps largely identified common regions of homology, while the EagI-generated map showed reduced power to identify homology and was excluded from further analysis. When compared to the in silico map of strain MG1655, the H10407 chromosome appeared remarkably similar to the MG1655 chromosome except at a few discrete regions where deletions, insertions or mismatched regions of varying sizes were observed (Fig. 1a). Unlike the genome structure of EHEC, UPEC and Shigella strains, where the collinearity with the E. coli K12 genome is broken by numerous inversions and translocations (Hayashi et al., 2001; Jin et al., 2002; Wei et al., 2003; Perna et al., 2001; Welch et al., 2002), which contribute to significant dissimilarity in the restriction map profile, no such rearrangements were seen in the strain H10407 genomic optical map. Due to the nature of measuring map homology, small differences tend to be missed and not confidently defined. Only differences larger than $10 \mathrm{~kb}$ are schematically outlined in Fig. 1(a) and listed in Table 3.

The BamHI-generated optical map indicates two regions on the strain H10407 optical map where deletions have occurred in relation to the map of E. coli K-12. These are designated D1 ( $\sim 25 \mathrm{~kb})$ and D2 ( $21 \mathrm{~kb})$ in Fig. 1(a) and Table 3. In the BsiWI-generated map, the deletions appear as mismatched gaps, although the size differences of the gaps between the H10407 optical map and the K-12 map amounts to the loss of $\sim 24 \mathrm{~kb}$ and $\sim 21 \mathrm{~kb}$ DNA at D1 and D2 (Table 3). D1 corresponds to the region of prophage Rac and D2 corresponds to the region with the Qin loci in strain MG1655. The absence of these two prophages in strain H10407 has been previously confirmed by a DNA microarray study (Fukiya et al., 2004).

The inserted sequences in the H10407 chromosome (I1-I7; Fig. 1a and Table 3) are local events and do not reflect translocated or duplicated regions of the backbone sequences. Bacterial genomes are quite dynamic and often acquire new genes or gene islands from phages or other species through horizontal transfer. In several instances, these acquired genes are seen in more than one pathogenic strain within the same species as well as in different species, such as the LEE island genes seen in EPEC and EHEC strains, and the type III secretion system seen in many Gram-negative bacteria. Thus, annotation of the inserted regions in the H10407 chromosome was attempted by comparison of its optical map with the in silico maps of E. coli K-12 as well as those of other E. coli pathogens using relaxed settings for map homology. According to the sequence data of the $g s p$ loci, inserted sequence region I5 overlaps the pheV tRNA gene sequence in E. coli $\mathrm{K}-12$ and should contain the $11.7 \mathrm{~kb}$ GSP island in the ETEC chromosome (Tauschek et al., 2002). The $\sim 45 \mathrm{~kb}$ I6 region on the optical map coincides with the selC tRNA locus on the $E$. coli genome. Previous work has demonstrated that a $45 \mathrm{~kb}$ sequence is integrated at the selC tRNA locus in ETEC and contains the tia and leoA genes, as well as several hypothetical and unknown ORFs (Fleckenstein et al., 2000). This means that the I6 region on the optical map corresponds to the inserted tia-leoA sequence. We could not confidently predict the content of the other insertions since either there was no match to reference strains at map level, or the match by one enzyme map could not be validated by another enzyme map. We anticipate that many of the H10407-specific sequences isolated by SSH will be located at these inserted sequence regions as well as at the mismatched gap regions identified on the H10407 optical map.

Four regions on the H10407 chromosome were identified as mismatched gaps relative to E. coli $\mathrm{K}-12$ (G1 G4 in Fig. 1a and Table 3). G1 and G4 are located at the ends of the linearized chromosome and probably reflect a single mismatched gap $(\mathrm{G} 1+\mathrm{G} 4)$ on the circular chromosome. The term 'mismatched gap' is being applied to regions on the optical map where the restriction sites between the two maps show no similarities over a stretch of the genome. Map homology reappears on either side of the mismatched gap region. All three regions of mismatched gaps in $\mathrm{H} 10407$ are larger than the corresponding regions in E. coli K-12 and the extra DNA at these sites contributes to the greater length of the ETEC genome. The extra DNA could include single and/ or multiple copies of novel gene sequences, pseudogenes, IS elements, phage and prophage genes. Annotation of the mismatched gap regions indicates that these sites overlap phage and prophage sequences present in the K-12 strain genome, including cryptic prophage CP4-6 in the G2 region, CP4-44 in G3 and KpLE2 phage-like element in G1 + G4. A recent microarray study has shown that several ORFs corresponding to these prophages are missing in strain $\mathrm{H} 10407$ (Fukiya et al., 2004), signifying that the mismatched gap regions are made up of both gene loss and gene gain. It is also interesting to note that $\mathrm{G} 1+\mathrm{G} 4$ overlap thrW, phe $U$ and leuX tRNA sequences and G3 overlaps asnT tRNA sequence on the E. coligenome. This is significant because several PAIs have inserted adjacent to these sequences in EPEC, EHEC, Shigella and UPEC strains. We predict that most of the genes corresponding to the unique sequences in the H10407 SSH 

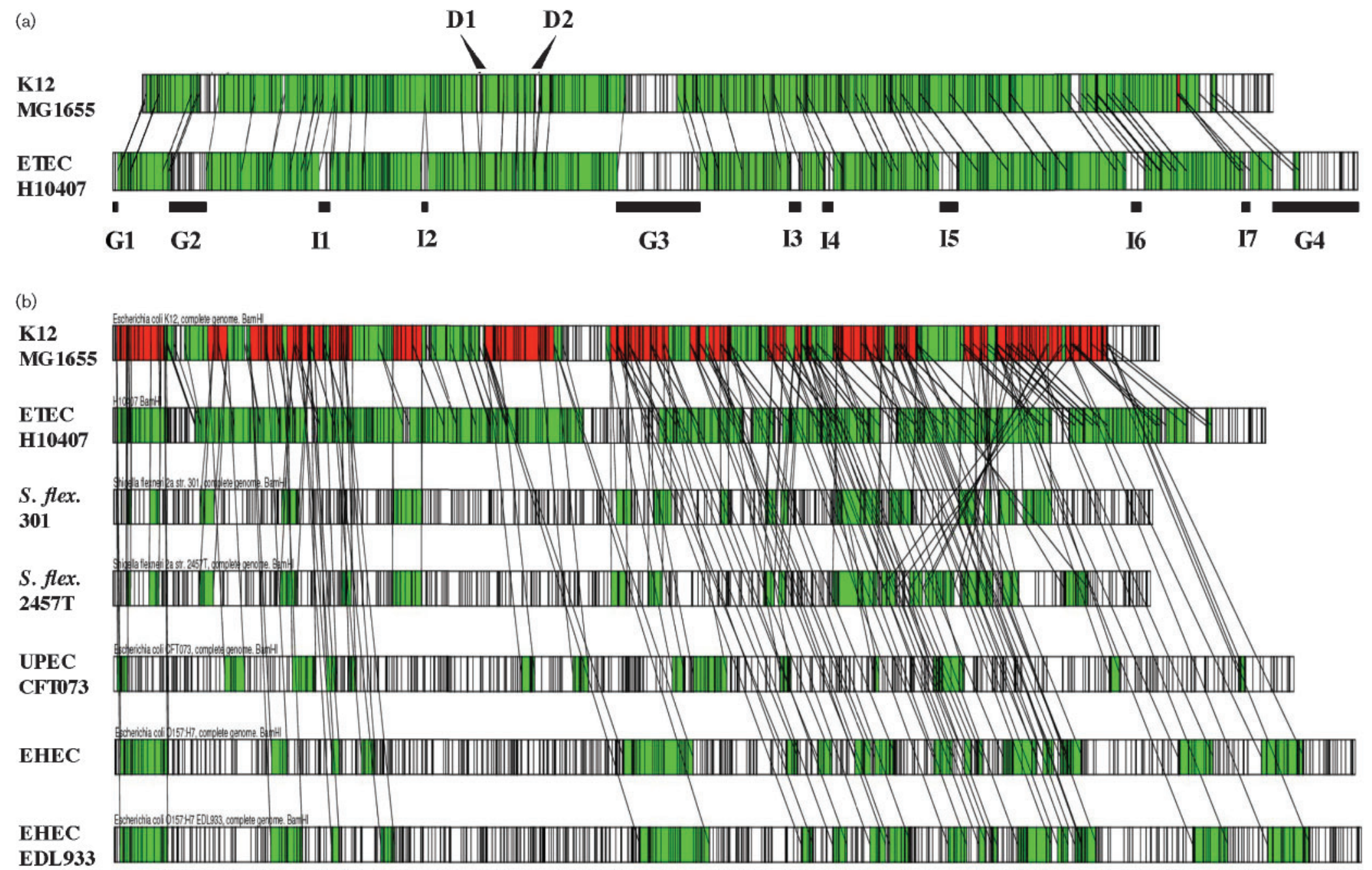

Fig. 1. Genome-wide optical map comparison. (a). The BamHI in silico map of E. coli K-12 MG1655 was compared to the optical map of ETEC $\mathrm{H} 10407$. (b). The BamHI in silico map of E. coli K-12 was compared to the optical map of ETEC H10407, and the in silico maps of S. flexneri strain 301, S. flexneri 2a strain 2457T, UPEC strain CFT073, and EHEC strains O157:H7 (from Sakai outbreak) and O157:H7 EDL933. Single matched areas are shown in green, multiple match areas in red, and non-match areas in white. G-mismatch gap: I, insertion; D deletion. The gaps and insertions of strain $\mathrm{H} 10407$ are underlined. The deletions of strain $\mathrm{H} 10407$ are indicated by solid triangles at the corresponding positions of $E$. coli $\mathrm{K}-12$. 
Table 3. Identification of mismatched gaps, deletions and insertions of ETEC H10407 relative to E. coli K-12 MG1655 by optical mapping

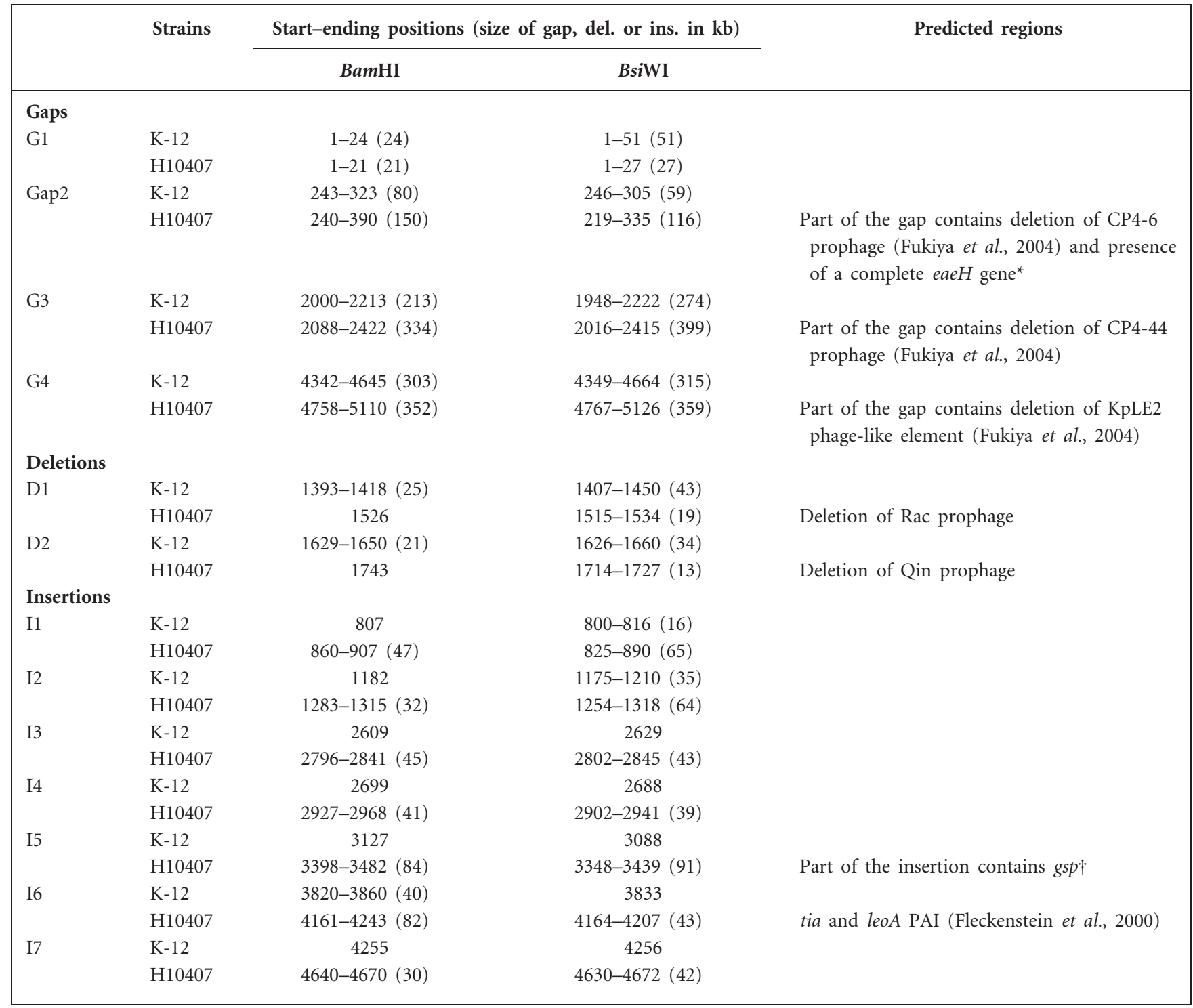

${ }^{\star}$ The placement of the eaeH gene in H10407 is based on the location of the truncated eaeH gene in E. coli K-12.

$\dagger$ The placement of $g s p$ island for type II secretion pathway, is based on the sequence done by Tauschek et al. (2002, GenBank accession no. AY056599).

library will be located at the insertion sites (I1-I7) and mismatched gap regions (G1-G4) identified in this study.

\section{H10407 chromosome is highly homologous to E. coli K-12}

In order to validate the efficacy of using optical maps to evaluate genomic variation, the in silico map of strain MG1655 was also compared with the in silico maps of the chromosomes of S. flexneri 2a strains 2457T and 301, UPEC strain CFT073, and EHEC strains O157 : H7 and O157: H7 EDL933 (Fig. 1b). In contrast to the high degree of map homology observed between strains H10407 and MG1655, these E. coli pathogens show a much lower degree of map homology, $12 \sim 34 \%$, to strain MG1655 (Fig. 1b, Table 4). Previously, genome sequence comparison has shown that $74 \sim 85 \%$ of the genome of the different $E$. coli pathogens contain E. coli K-12 backbone sequences (Hayashi et al., 2001; Jin et al., 2002; Perna et al., 2001; Wei et al., 2003; Welch et al., 2002). Reduced restriction-enzyme-site-based map homology suggests that significant restriction enzyme site polymorphism has occurred due to vertically acquired mutations, deletions, acquisition of DNA and gross rearrangements on the genome of the different E. coli pathogens. Using a less stringent programme for comparing such maps, Zhou et al. (2004a) predicted that the S. flexneri 2a 
Table 4. Correlation of optical map-based chromosomal homology to sequence identity

\begin{tabular}{|lccc|}
\hline Strain & \multicolumn{2}{c|}{ Map identity (\%)* } & $\begin{array}{c}\text { Sequence } \\
\text { identity (\%) }\end{array}$ \\
\cline { 2 - 3 } & BamHI & BsiWI & \\
\hline E. coli H10407 & 77 & 76 & $96 \dagger$ \\
S. flexneri 301 & 26 & 20 & $85 \ddagger$ \\
S. flexneri 2a 2457T & 28 & 23 & $82 \#$ \\
E. coli CFT073 & 18 & 12 & $75 \S$ \\
E. coli O157 : H7 & 32 & 34 & 759 \\
E. coli O157 : H7 EDL933 & 32 & 32 & $74 \#$ \\
\hline
\end{tabular}

*The in silico map of MG1655 was compared with the optical map of strain $\mathrm{H} 10407$ and the in silico restriction maps of the sequenced genomes of the other pathogenic strains. Homology to strain MG1655 was identified under the default scores. The percentage map identity for each strain is $100 \times$ (total length of homologous regions)/(length of the chromosome).

$\dagger$ Predicted based on a theoretical model curve correlating percentage map identity to percentage sequence identity and derived from known genome sequences of E. coli pathogens and in silico-derived restriction maps. The curve is based on the assumption that each base pair match is independent of any of the other matches, and that the variation between two genomes is randomly distributed across the genome. Whether these assumptions hold will depend on more work to be done to quantify differences between genomes at the map level and at the sequence level. At this point, these data are not readily available; hence the model curve is at best a working model. †Jin et al. (2002).

\#Wei et al. (2003).

\$Welch et al. (2002).

SHayashi et al. (2001).

\#Perna et al. (2001).

genome sequence is $47 \%$ similar to that of E. coli K-12. However, using a more stringent programme to compare sequences, as has been done in our study, the Shigella genome is $28 \%$ similar to that of E. coli K-12, as mentioned above. In striking contrast, the BamHI- and BsiWIgenerated optical maps of $\mathrm{H} 10407$ show $77 \%$ and $76 \%$ similarity to the E. coli $\mathrm{K}-12$ genome, respectively, suggesting that fewer restriction enzyme site polymorphisms have occurred on the ETEC chromosome (Fig. 1b, Table 4). Based on the high level of optical-map-based similarity between the genome of ETEC and E. coli K-12, comparisons with other sequenced genomes and working with a model curve that correlates sequence identity with map identity (Table 4), one can make a tentative prediction that the two genomes share $>96 \%$ sequence similarity, a prediction that awaits confirmation from the availability of the completed ETEC genome sequence.

\section{DISCUSSION}

The whole genome sequence of ETEC strain H10407 (currently being sequenced) will aid in the complete characterization and localization of the genes that comprise the group I-V category of sequences isolated by SSH. Based on the strikingly high genomic map homology between strain $\mathrm{H} 10407$ and E. coli K-12, we predict that most of these sequences, as well as additional gene sequences that may be identified, will reside at the few discrete regions identified on the H10407 optical map where the genome differs from E. coli K-12. Besides unique chromosomal sequences, strain $\mathrm{H} 10407$ has four plasmids, a non-conjugative $92 \mathrm{~kb}$ plasmid (NTP113 or pCS1) that encodes the CFA/I, ST1b, astA, which encodes an enterotoxin EAST1, the autotransporter gene eat $A$, and longus, a type IV pilus-encoding gene, a conjugative $64 \mathrm{~kb}$ plasmid (NTP104 or pYJ11) that encodes LT and reportedly a second ST gene, a second $64 \mathrm{~kb}$ plasmid (pTRA1) and a $6 \mathrm{~kb}$ plasmid of unknown composition. The complete sequence of the ETEC plasmids, when available, might demonstrate the presence of additional virulence-associated genes.

The chromosomal SSH library contains several sequences that are representative of genes seen in the genomes and PAIs of other E. coli pathogenic strains. These are carbohydrateutilizing and fatty acid biosynthesis genes, adhesins, autotransporters, various restriction-modification systems, and hypothetical and unknown genes. However, the optical map suggests that large-scale acquisition of H10407-specific islands of genes, or the extensive gene duplications, inversions and translocations that contribute to the genomic variation previously reported in the genomes of other $E$. coli pathogens, has not occurred in strain H10407. Furthermore, the backbone sequence of the ETEC chromosome is almost identical to that of E. coli K-12, indicating that few vertically acquired base pair substitutions have occurred in conserved genes. Therefore, from an evolutionary standpoint, the main event in the derivation of ETEC from E. coli occurred with the acquisition of virulence plasmids encoding CF adhesins and enterotoxins. Similar observations have been made for Shigella, EHEC and other pathogens, although more extensive alterations have occurred in the genomes of these pathogens. Pathogenic E. coli such as EHEC, UPEC, EPEC and Shigella strains, have evolved through a complex process. While the E. coli backbone has undergone slow accumulation of vertically acquired changes, numerous independent horizontal gene transfer events at discrete sites have conferred unique pathogenic properties to each E. coli pathogen. The result is a mosaic genome structure where a core E. coli signature chromosome that maintains its characteristic physiology is punctuated by combinations of islands of genes that confer to each pathogenic strain a characteristic disease-causing lifestyle. For example, a comparison of the EHEC O157 : H7 EDL933 genome sequence with E. coli $\mathrm{K}-12$ revealed a surprising level of diversity between two members of the same species. Although they shared a common collinear backbone sequence, interrupted by a single $422 \mathrm{~kb}$ inversion, hundreds of islands of EHECspecific DNA (O-islands, total 1.34 Mb encoding 1387 new genes) and loss of K-12-specific sequences (K-islands, total $0.53 \mathrm{Mb}$ ) are distributed throughout both genomes (Perna 
et al., 2001). The O-islands contained genes encoding putative virulence factors such as toxins, urease genes, a type III secretion system with associated substrates and effector proteins, the LEE island, a fatty acid biosynthesis system and adhesins. About $33 \%$ of the O-islands contain genes of unknown function. A similar pattern of variation was seen in the genome sequence of UPEC strain CFT073, which is $590 \mathrm{~kb}$ longer than strain K-12: it had 247 CFT073-specific DNA segments $>50 \mathrm{bp}$ and 60 segments $>4 \mathrm{~kb}$ encoding potential virulence genes, inserted or substituted into a conserved backbone sequence (Welch et al., 2002). The atypical base composition of most of the islands in EHEC, UPEC and Shigella indicate that they were acquired by horizontal transfers. Single nucleotide polymorphisms are distributed throughout the homologous backbone, contributing to the restriction enzyme site polymorphism, and as expected most differences are synonymous changes at third codon positions (Perna et al., 2001). The number of Shigella-specific islands is smaller than those in E. colistrains CFT073 and EDL933, and a larger proportion of the genome ( $82 \%)$ is backbone compared to $75 \%$ for strains CFT073 and EDL933 (Wei et al., 2003). Based on the optical map homology described in this study, the H10407 chromosome is much more similar to that of strain MG1655 than to strain CFT073, S. flexneri 2a or EHEC. Fewer backbone substitutions and changes have occurred and the ETEC chromosome is predicted to be $>96 \%$ identical in sequence to the E. coli $\mathrm{K}-12$ chromosome.

Many pathogen-specific island locations are at the same relative backbone positions although the island contents are unrelated. For example, at the selC tRNA site, strain $\mathrm{H} 10407$ has a $45 \mathrm{~kb}$ island of genes that include the tia and leoA genes, EPEC and EHEC strains contain the LEE PAI, UPEC strain 536 has PAI-I, Salmonella has SPI-3 and Shigella has the SHI-2 island of genes (Schmidt \& Hensel, 2004). This pattern of insertion at tRNA gene sites, which are also frequently associated with phage attachment sites, is typical of many horizontally acquired PAIs and genes. The molecular basis for this insertion is not completely understood. One hypothesis suggests that the tRNA gene structure provides a conserved motif for the integration of PAIs and phages (Reiter et al., 1989).

The difference in genome size between strains $\mathrm{H} 10407$ and $E$. coli $\mathrm{K}-12$ can be accounted for by summing up the differences between the mismatched gap regions and insertions as well as the deletions. The SSH library of sequences does not comprise complete genes. Nor is the SSH library in this study a complete representation of all unique chromosomal sequences in strain H10407. The sequences in the SSH library constitute $\sim 60 \mathrm{~kb}$ of unique strain $\mathrm{H} 10407$ sequences. If a mean E. coliORF is assumed to be about 800 bp and the mean size of the insert fragments in the SSH library is $\sim 390 \mathrm{bp}$, then the SSH library accounts for a minimum of $\sim 120 \mathrm{~kb}$ of unique gene sequences. However, redundancies in bacterial genes, phage, prophage, transposases and IS elements are common in enterobacterial genomes and may add to the increased length of the genome. We do not know which of the SSH sequences identified in this study are linked as island genes on the H10407 chromosome. That information will come from genome sequencing analysis.

It is interesting to note that ETEC strain B7A $(\mathrm{O} 148: \mathrm{H} 28$, CS6) lacks several H10407-specific chromosomal sequences in addition to the absence of three previously described genes eatA, tia and tibA. Many studies around the world have shown that ETEC-induced diarrhoea may range from the very mild to the very severe (Qadri et al., 2005). Reliable and reproducible animal models are lacking for studying human ETEC infections and comparing the virulence of different strains. In human challenge studies, strain B7A has been consistently less virulent than strain H10407. Strain B7A required 20-fold more organisms $\left(1 \times 10^{10}\right.$ c.f.u. $)$ than strain $\mathrm{H} 10407\left(5 \times 10^{8}\right.$ c.f.u.) to induce diarrhoea in orally challenged human volunteers. Likewise, while strain H10407 caused diarrhoea in $100 \%$ of volunteers, strain B7A produced diarrhoea in only $67 \%$, despite the higher dose (Levine et al., 1979; Byrd et al., 2003). While differences in CF type (CFA/I vs CS6), $\mathrm{O}$ and $\mathrm{H}$ antigens may account for some of the reduced virulence in strain B7A, lack of H10407-specific sequences may also explain differences in virulence properties. The variable occurrence of H10407specific sequences, not only in strain B7A but also in other ETEC strains, indicates that there is probably a greater heterogeneity among ETEC strains than previously described. The optical map of strain H10407 can be compared with similar maps from other ETEC strains to determine the level of microbial variation as well as identify regions on the chromosome that may be hypervariable.

Our results with SSH and optical mapping generally corroborate data obtained using other approaches. Using comparative genomic hybridization, labelled genomic DNA from 22 pathogenic E. coli strains including strain H10407 were hybridized to an E. coli K-12 microarray (Fukiya et al., 2004). Thirty per cent of the ORFs in the following five categories were frequently absent: cell envelope, central intermediary metabolism, energy metabolism, transport and binding proteins, and hypothetical and some regulatory genes. There were differences in the number of absent ORFs in the different strains and it is interesting to note that on average, the two ETEC strains tested had the least number of absent ORFs (230 in strain H10407 and 286 in ETEC 3110) compared to the other E. coli pathogens, confirming that ETEC has undergone fewer chromosomal changes compared to Shigella, UPEC or EPEC strains. Microarray analysis indicated that less than $10 \%$ of the E. coli K-12 prophages were present in the pathogenic E. coli including strain H10407, and this loss will also contribute to the observed genetic variation. Most of the ORFs of the prophages CP4-6 and CP4-57 were absent in the E. coli pathogens. The $r f a$ and $r f b$ gene clusters of E. coli K-12 involved in core and $\mathrm{O}$-antigen biosynthesis were frequently absent in pathogenic strains. Such losses and gains of pathogen-specific sequences in the H10407 chromosome 
would account for the differences seen by optical mapping analysis.

\section{ACKNOWLEDGEMENTS}

We thank Cheryl P. Ewing for help with DNA sequencing and Jeffrey Chiang for PCR amplification of DNA used in dot blots. We thank Dr Marcia Wolf for providing H10407 strain and Drs Ryan Ranallo, Marcia Wolf and Patricia Guerry for their critical reading of the manuscript. We thank Thomas L. Hale for support of this project. Adam M. Briska from OpGen Inc. is gratefully acknowledged for many suggestions regarding optical map analysis. The content of this publication does not necessarily reflect the views or policies of the Department of Health and Human Services, the US Department of the Army or Navy, or the US Department of Defence, nor does the mention of trade names, commercial products, or organizations imply endorsement by the US Government.

\section{REFERENCES}

Arduino, R. C. \& DuPont, H. L. (1993). Travellers' diarrhoea. Baillieres Clin Gastroenterol 7, 365-385.

Blattner, F. R., Plunkett, G., 3rd, Bloch, C. A. \& 14 other authors (1997). The complete genome sequence of Escherichia coli K-12. Science 277, 1453-1474.

Byrd, W., Mog, S. R. \& Cassels, F. J. (2003). Pathogenicity and immune response measured in mice following intranasal challenge with enterotoxigenic Escherichia coli strains H10407 and B7A. Infect Immun 71, 13-21.

Cai, W., Jing, J., Irvin, B. \& 8 other authors (1998). High-resolution restriction maps of bacterial artificial chromosomes constructed by optical mapping. Proc Natl Acad Sci U S A 95, 3390-3395.

Cartwright, R. Y. (1993). Travellers' diarrhoea. Br Med Bull 49, 348-362.

Diatchenko, L., Lau, Y. F., Campbell, A. P. \& 8 other authors (1996). Suppression subtractive hybridization: a method for generating differentially regulated or tissue-specific cDNA probes and libraries. Proc Natl Acad Sci U S A 93, 6025-6030.

Dobrindt, U. \& Reidl, J. (2000). Pathogenicity islands and phage conversion: evolutionary aspects of bacterial pathogenesis. Int J Med Microbiol 290, 519-527.

Dobrindt, U., Agerer, F., Michaelis, K. \& 7 other authors (2003). Analysis of genome plasticity in pathogenic and commensal Escherichia coli isolates by use of DNA arrays. J Bacteriol 185, 1831-1840.

Elsinghorst, E. A. \& Kopecko, D. J. (1992). Molecular cloning of epithelial cell invasion determinants from enterotoxigenic Escherichia coli. Infect Immun 60, 2409-2417.

Elsinghorst, E. A. \& Weitz, J. A. (1994). Epithelial cell invasion and adherence directed by the enterotoxigenic Escherichia coli tib locus is associated with a 104-kilodalton outer membrane protein. Infect Immun 62, 3463-3471.

Evans, D. G., Silver, R. P., Evans, D. J., Jr, Chase, D. G. \& Gorbach, S. L. (1975). Plasmid-controlled colonization factor associated with virulence in Escherichia coli enterotoxigenic for humans. Infect Immun 12, 656-667.

Evans, D. J., Jr \& Evans, D. G. (1973). Three characteristics associated with enterotoxigenic Escherichia coli isolated from man. Infect Immun 8, 322-328.

Fleckenstein, J. M., Kopecko, D. J., Warren, R. L. \& Elsinghorst, E. A. (1996). Molecular characterization of the tia invasion locus from enterotoxigenic Escherichia coli. Infect Immun 64, 2256-2265.
Fleckenstein, J. M., Lindler, L. E., Elsinghorst, E. A. \& Dale, J. B. (2000). Identification of a gene within a pathogenicity island of enterotoxigenic Escherichia coli $\mathrm{H} 10407$ required for maximal secretion of the heat-labile enterotoxin. Infect Immun 68, 2766-2774.

Freedman, D. J., Tacket, C. O., Delehanty, A., Maneval, D. R., Nataro, J. \& Crabb, J. H. (1998). Milk immunoglobulin with specific activity against purified colonization factor antigens can protect against oral challenge with enterotoxigenic Escherichia coli. J Infect Dis 177, 662-667.

Fukiya, S., Mizoguchi, H., Tobe, T. \& Mori, H. (2004). Extensive genomic diversity in pathogenic Escherichia coli and Shigella strains revealed by comparative genomic hybridization microarray. J Bacteriol 186, 3911-3921.

Gilligan, P. H. (1999). Escherichia coli. EAEC, EHEC, EIEC, ETEC. Clin Lab Med 19, 505-521.

Gupta, A., Phung, L. T., Taylor, D. E. \& Silver, S. (2001). Diversity of silver resistance genes in IncH incompatibility group plasmids. Microbiology 147, 3393-3402.

Hayashi, T., Makino, K., Ohnishi, M. \& 19 other authors (2001). Complete genome sequence of enterohemorrhagic Escherichia coli O157:H7 and genomic comparison with a laboratory strain K-12. DNA Res 8, 11-22.

Jerse, A. E., Yu, J., Tall, B. D. \& Kaper, J. B. (1990). A genetic locus of enteropathogenic Escherichia coli necessary for the production of attaching and effacing lesions on tissue culture cells. Proc Natl Acad Sci U S A 87, 7839-7843.

Jin, Q., Yuan, Z., Xu, J. \& 30 other authors (2002). Genome sequence of Shigella flexneri 2a: insights into pathogenicity through comparison with genomes of Escherichia coli K12 and O157. Nucleic Acids Res 30, 4432-4441.

Knutton, S., Lloyd, D. R. \& McNeish, A. S. (1987). Identification of a new fimbrial structure in enterotoxigenic Escherichia coli (ETEC) serotype O148: H28 which adheres to human intestinal mucosa: a potentially new human ETEC colonization factor. Infect Immun 55, 86-92.

Lai, Z., Jing, J., Aston, C. \& 12 other authors (1999). A shotgun optical map of the entire Plasmodium falciparum genome. Nat Genet 23, 309-313.

Levine, M. M., Nalin, D. R., Hoover, D. L., Bergquist, E. J., Hornick, R. B. \& Young, C. R. (1979). Immunity to enterotoxigenic Escherichia coli. Infect Immun 23, 729-736.

Levine, M. M., Kaper, J. B., Black, R. E. \& Clements, M. L. (1983). New knowledge on pathogenesis of bacterial enteric infections as applied to vaccine development. Microbiol Rev 47, 510-550.

Levine, M. M., Ristaino, P., Marley, G. \& 8 other authors (1984). Coli surface antigens 1 and 3 of colonization factor antigen II-positive enterotoxigenic Escherichia coli: morphology, purification, and immune responses in humans. Infect Immun 44, 409-420.

Lim, A., Dimalanta, E. T., Potamousis, K. D. \& 16 other authors (2001). Shotgun optical maps of the whole Escherichia coli O157: H7 genome. Genome Res 11, 1584-1593.

Lin, J., Qi, R., Aston, C. \& 8 other authors (1999). Whole-genome shotgun optical mapping of Deinococcus radiodurans. Science 285, 1558-1562.

Lindenthal, C. \& Elsinghorst, E. A. (1999). Identification of a glycoprotein produced by enterotoxigenic Escherichia coli. Infect Immun 67, 4084-4091.

McConnell, M. M., Hibberd, M., Field, A. M., Chart, H. \& Rowe, B. (1990). Characterization of a new putative colonization factor (CS17) from a human enterotoxigenic Escherichia coli of serotype O114: H21 which produces only heat-labile enterotoxin. J Infect Dis 161, 343-347.

Myers, E. W. \& Huang, X. (1992). An O (N2 log N) restriction map comparison and search algorithm. Bull Math Biol 54, 599-618. 
Patel, S. K., Dotson, J., Allen, K. P. \& Fleckenstein, J. M. (2004). Identification and molecular characterization of EatA, an autotransporter protein of enterotoxigenic Escherichia coli. Infect Immun 72, 1786-1794.

Perna, N. T., Mayhew, G. F., Posfai, G., Elliott, S., Donnenberg, M. S., Kaper, J. B. \& Blattner, F. R. (1998). Molecular evolution of a pathogenicity island from enterohemorrhagic Escherichia coli O157: H7. Infect Immun 66, 3810-3817.

Perna, N. T., Plunkett, G., 3rd, Burland, V. \& 25 other authors (2001). Genome sequence of enterohaemorrhagic Escherichia coli O157: H7. Nature 409, 529-533.

Qadri, F., Svennerholm, A. M., Faruque, A. S. \& Sack, R. B. (2005). Enterotoxigenic Escherichia coli in developing countries: epidemiology, microbiology, clinical features, treatment, and prevention. Clin Microbiol Rev 18, 465-483.

Reid, R. H., Boedeker, E. C., McQueen, C. E. \& 8 other authors (1993). Preclinical evaluation of microencapsulated CFA/II oral vaccine against enterotoxigenic E. coli. Vaccine 11, 159-167.

Reiter, W. D., Palm, P. \& Yeats, S. (1989). Transfer RNA genes frequently serve as integration sites for prokaryotic genetic elements. Nucleic Acids Res 17, 1907-1914.

Reslewic, S., Zhou, S., Place, M. \& 11 other authors (2005). Wholegenome shotgun optical mapping of Rhodospirillum rubrum. Appl Environ Microbiol 71, 5511-5522.

Sambrook, J. \& Russell, W. D. (2001). Molecular Cloning: a Laboratory Manual, 3rd edn. Cold Spring Harbor, NY: Cold Spring Harbor Laboratory.

Schmidt, H. \& Hensel, M. (2004). Pathogenicity islands in bacterial pathogenesis. Clin Microbiol Rev 17, 14-56.

Sherlock, O., Vejborg, R. M. \& Klemm, P. (2005). The TibA adhesin/ invasin from enterotoxigenic Escherichia coli is self recognizing and induces bacterial aggregation and biofilm formation. Infect Immun 73, 1954-1963.

Smith, H. R., Cravioto, A., Willshaw, G. A., McConnell, M. M., Scotland, S. M., Gross, R. J. \& Rowe, B. (1979). A plasmid coding for the production of colonisation factor antigen I and heat-stable enterotoxin in strains of Escherichia coli of serogroup O78. FEMS Microbiol Lett 6, 255-266.

Smyth, C. J. (1982). Two mannose-resistant haemagglutinins on enterotoxigenic Escherichia coli of serotype O6:K15:H16 or $\mathrm{H}-$ isolated from travellers' and infantile diarrhoea. J Gen Microbiol 128, 2081-2096.
Tacket, C. O., Losonsky, G., Link, H., Hoang, Y., Guesry, P., Hilpert, H. \& Levine, M. M. (1988). Protection by milk immunoglobulin concentrate against oral challenge with enterotoxigenic Escherichia coli. N Engl J Med 318, 1240-1243.

Tang, M. \& Waterman, M. S. (2001). Local matching of random restriction maps. J Appl Probab 38, 335-356.

Tauschek, M., Gorrell, R. J., Strugnell, R. A. \& Robins-Browne, R. M. (2002). Identification of a protein secretory pathway for the secretion of heat-labile enterotoxin by an enterotoxigenic strain of Escherichia coli. Proc Natl Acad Sci U S A 99, 7066-7071.

Waterman, M. S., Smith, T. F. \& Katcher, H. L. (1984). Algorithms for restriction map comparisons. Nucleic Acids Res 12, 237-242.

Wei, J., Goldberg, M. B., Burland, V. \& 14 other authors (2003). Complete genome sequence and comparative genomics of Shigella flexneri serotype 2a strain 2457T. Infect Immun 71, 2775-2786.

Welch, R. A., Burland, V., Plunkett, G. \& 16 other authors (2002). Extensive mosaic structure revealed by the complete genome sequence of uropathogenic Escherichia coli. Proc Natl Acad Sci U S A 99, 17020-17024.

Wenneras, C. \& Erling, V. (2004). Prevalence of enterotoxigenic Escherichia coli-associated diarrhoea and carrier state in the developing world. J Health Popul Nutr 22, 370-382.

Winstanley, C. (2002). Spot the difference: applications of subtractive hybridisation to the study of bacterial pathogens. J Med Microbiol 51, 459-467.

Wolf, M. K. (1997). Occurrence, distribution, and associations of O and $\mathrm{H}$ serogroups, colonization factor antigens, and toxins of enterotoxigenic Escherichia coli. Clin Microbiol Rev 10, 569-584.

Wolf, M. K., Taylor, D. N., Boedeker, E. C., Hyams, K. C., Maneval, D. R., Levine, M. M., Tamura, K., Wilson, R. A. \& Echeverria, P. (1993). Characterization of enterotoxigenic Escherichia coli isolated from U.S. troops deployed to the Middle East. J Clin Microbiol 31, 851-856.

Yamamoto, T. \& Yokota, T. (1983). Plasmids of enterotoxigenic Escherichia coli H10407: evidence for two heat-stable enterotoxin genes and a conjugal transfer system. J Bacteriol 153, 1352-1360.

Zhou, S., Kile, A., Bechner, M. \& 13 other authors (2004a). Singlemolecule approach to bacterial genomic comparisons via optical mapping. J Bacteriol 186, 7773-7782.

Zhou, S., Kile, A., Kvikstad, E. \& 11 other authors (2004b). Shotgun optical mapping of the entire Leishmania major Friedlin genome. Mol Biochem Parasitol 138, 97-106. 